\title{
Contributions of Social Networks to Health and Care Services in Myanmar's Older Adult Population: 2012 Myanmar Aging Study
}

\author{
Paul Kowal1,2*, Min Nwe Tun ${ }^{3}$, Sai Kham Leik ${ }^{4}$, Ilaria Rocco ${ }^{5}$ \\ ${ }^{1}$ Centre for Women's Health Research, University of Newcastle, Newcastle, Australia \\ ${ }^{2}$ Research Institute for Health Sciences, Chiang Mai University, Chiang Mai, Thailand \\ ${ }^{3}$ Independent Consultant in Public Health, Yangon, Myanmar \\ ${ }^{4}$ Mahidol University, Bangkok, Thailand \\ ${ }^{5}$ National Research Council, Institute of Neuroscience (CNR-IN), Padova, Italy \\ Email: *paul.kowal@newcastle.edu.au
}

How to cite this paper: Kowal, P., Tun, M.N., Leik, S.K. and Rocco, I. (2021) Contributions of Social Networks to Health and Care Services in Myanmar's Older Adult Population: 2012 Myanmar Aging Study. Health, 13, 1530-1545.

https://doi.org/10.4236/health.2021.1312109

Received: June 30, 2021

Accepted: December 28, 2021

Published: December 31, 2021

Copyright ( 2021 by author(s) and Scientific Research Publishing Inc. This work is licensed under the Creative Commons Attribution International License (CC BY 4.0).

http://creativecommons.org/licenses/by/4.0/

\begin{abstract}
Background: Myanmar's National Health Plan 2017-2021 set out concrete steps to strengthen the health system on the way to achieving the goal of universal health coverage by 2030. Ensuring these steps include the 7.7 million older adults in Myanmar's population by 2030 will require novel strategies that improve health and reduce financial burden of health expenditures. An examination of the relationship between social networks and selected health outcomes was undertaken to determine whether these networks can safeguard older adults' continued contributions to family, society and their own health. Methods: Secondary analysis of a nationally representative study of adults aged 60 years and older. Ordered logistic regression analyses with weighted data were used to examine the relationship between a social network variable and a number of health outcomes. Findings: Stronger social networks were associated with better health outcomes like better memory (OR 1.2), lower reported walking difficulties (OR 0.58), better self-reported health ( $R$ 1.15). People with higher social ties were also more like to receive regular assistance and provide care for other household members. Interpretation: Social networks play a role in mediating health outcomes and interactions with the health care systems. Social network interventions should be explored as part of policy mechanisms to ensure universal health coverage for older adults in Myanmar.
\end{abstract}

\section{Keywords}

Myanmar, Ageing, Health, Health Policy, Social Networks, UHC, UN SDGs 


\section{Introduction}

The cumulative growth on health spending in Myanmar was more than twice the income growth between 2007 and 2017 [1]. While this represents a positive policy shift in Myanmar, current health expenditure as a percent of GDP started from a low baseline (1.7\% of GDP in 2007, reaching 4.7\% in 2017). A large portion of health care is financed by individuals and families, with $76 \%$ of health costs from out-of-pocket payments in 2017 [2] and very low health insurance coverage [3] [4] [5] (see Supplemental Figure S1). To pay for care, households typically use a combination of savings, selling consumables, selling assets and borrowing money to finance this expenditure [6] [7]. This typically means reliance on one's self, family and social networks. For chronic health conditions that need ongoing and long-term treatment, the costs of care pose a considerable challenge for families, communities and policy makers.

The disease and financial challenges are high and growing in Myanmar. Chronic conditions are the biggest burden on the health care system, accounting for $71 \%$ of all deaths and $78 \%$ of years lived with disability (YLDs) in 2017, increasing to $75 \%$ of deaths and $79 \%$ of YLDs in 2019 [8]. The rapidly changing economic situation is adding to the pressures through changing health risks for noncommunicable diseases (NCDs). In a recent study, nearly all adults in Myanmar reported at least one NCD risk factor (for instance, alcohol or tobacco consumption, high body mass index, low physical activity, high salt intake, high blood pressure, or low fruit and vegetable diet) [9] [10]. Higher disease and risk levels contributed to an increase in hospital admissions from NCDs in Myanmar between 2012 and 2017 [11]. One in four families with a member requiring hospitalization in Magway Region, Myanmar, faced catastrophic health expenditures [12].

The health transition created by an ageing population and the rapidly changing economic situation will contribute further pressures on the health system. By the year 2050 in Myanmar, the percentage of the population aged zero to 14 years will roughly equal the population aged 60 years and older (each at 19\%) [13] (see Supplemental Figure S2). This equates to approximately 5.4 million adults aged $60+$ in 2020 , increasing to 7.7 million in 2030 [13]. This means that plans for universal health coverage in Myanmar by 2030 will need to ensure additional 2.3 million older adults are accounted for in its calculations for both access and financial protection. Without immediate action to lower disease and risk prevalence, the NCD burden for the health system in 2030 will likely be even higher than current estimates [10] (see Supplemental Table S1).

Noting the relationship between NCDs and increasing age, and similarly the increased risk of economic vulnerability with increasing age, inclusion of older adults in efforts to extend the Basic Essential Package of Health Services (EPHS) and financial protection in the current Myanmar National Health Plan 20172021, will contribute to achieving UHC by 2030 [14]. One action would be to identify factors that prevent disease (thereby decreasing need for health care ser- 
vices) and factors that increase the numbers of people who access primary health care when needed.

One such factor is social networks. The quantity and quality of social relationships are known to affect mental and physical health, health behaviours, and mortality risk [15]. Good connections and social support can improve health and increase longevity, as the web of social ties are a common source of access to a variety of resources [16]. Social network support and size of social networks have been shown to impact health—both negatively and positively [17] [18] [19]. Positive types of social networks can reinforce behavior changes that are needed to shift NCD risk factors. "Healthy behaviour can ripple through social networks, bringing the weight of group norms to bear on individual decisions" [20]. Equally, negative types may reinforce poor health outcomes [19]. This highlights the communicable nature of non-communicable diseases [21], and in turn, the potential for social networks to positively contribute to achieving UHC by both pushing people who need care into the system and by keeping people physically and mentally healthier (and reducing health care utilization). This was highlighted in the National Strategic Plan for Prevention and Control of NCDs (2017-2021) through two of the four thematic areas: health promotion (Healthy Setting Approach) and health system strengthening (reduce financial impact of NCDs, and empowering communities and patients in self-care [22]. The NCD Strategic Plan is aligned with the WHO NCD Global Action Plan (see Supplementary Table S2) - and uses targets similar to those outlined in the NCD Progress Monitor, but adapted for the context in Myanmar [23] [24].

Estimating the role of social networks in NCD burden and universal health coverage in Myanmar would contribute to achieving national health policy goals. Data from a national study was used to determine whether the size of social networks impacts health outcomes that are related to health service utilization for men and women. These results will be important to inform the next 5-year National Health Plan (2022-2026) and contribute to efforts to include older adults in health systems planning and policy over the next decade.

\section{Methods}

\subsection{Data Sources}

Responding directly to the Demand for Services sub-category, within the Service Delivery category for Strengthening Systems to Support Operationalization of the current Myanmar National Health Plan 2017-2021, analysis of data from the 2012 Myanmar Aging Study was undertaken to inform developments for the next National Health Plan (2022-2026). Data from this study were examined to explore the hypothesis that a larger number of social contacts (size of social network) has a positive impact on overall health and functioning, and influences health care utilization (positively for men, negatively for women).

The Myanmar Aging Survey sample consisted of 4080 persons aged 60 and was defined using a multi-stage sampling that involved selecting 60 townships 
and then 150 rural villages and 90 urban wards within them. Only one respondent aged 60 and older was randomly selected in each household. The response rate was $92.6 \%$ [25].

\subsection{Analysis}

A set of variables were used to examine how social networks impact intermediate health outcomes related to health systems interactions.

A working definition of social networks for this analysis was based on previous work [26] [27]. A social ties variable was generated to indicate "low" or "high" social networks. A score was generated from four dichotomized variables:

1) Living arrangements (1: not alone, 0 : alone);

2) Contacts (visits or phone calls) with adult children (1: At least weekly, 0: less frequent or not at all);

3) Social engagement (compiled from six categories: a) attend community meetings; b) offer food to monks; c) participate in political meetings or events; d) socialize with friends and neighbors, like chatting, eating together, or playing games; e) physical exercise in a group; f) attend community or religious ceremonies) (1: At least monthly, 0: less frequent or not at all); and,

4) Contacts with relatives (siblings, grandchildren or close relatives) (1: At least weekly, 0: less frequent or not at all).

Those with individual scores of 0 and 1 for each variable were combined for a final social ties score that ranged from 0 (lower level of social ties) to 4 (higher level of social ties).

Health system interaction proxies: A set of questions about health and healthrelated outcomes were used as proxy indicators for factors that drive interactions with the health system. These factors are influenced by social ties to different degrees and together they represent areas where interventions may keep individuals healthier (such as self-care or reducing the need for health services) or push them to get needed care (for example, identifying symptoms or conditions that often trigger someone to seek health care).

1) Self-reported health. Overall self-reported general health was assessed through the question, "How would you rate your physical health at the present time? Would you say it is very good, good, fair, poor or very poor?"

2) Memory. "How would you best describe your memory at present? Would you say it is very good, good, fair, poor or very poor?"

3) Providing care for other household members, "Excluding grandchildren, do you regularly take care of any other household member?"

4) Mobility, "Do you have any difficulty walking 200 - 300 meters? and "How much difficulty? (None, some, a lot, cannot do)"

5) Receive regular assistance, "When doing things to take care of yourself, like bathing or dressing or to carry on your daily activities, do you receive regular assistance from anyone?"

6) Illnesses/injuries that limit usual activities, "During the past 12 months, were there any times that you were sick or injured that prevented you from per- 
forming your usual activities?”

7) Bodily pains, "Overall, in the last 30 days, how much of bodily aches or pains did you have? (None, mild, moderate, severe)"

Descriptive characteristics are presented as frequencies and percentages for categorical variables. Chi-square tests were used to compare distribution of social ties score and health system interaction proxies.

Ordered logistic regression analysis was done to determine intermediate health outcomes associated with social networks while controlling for age, sex and highest education level completed. Weighted data have been used to account for sampling design. All the statistical analyses were performed using the SAS 9.4 software. Level of significance was set at $p=0.05$.

\section{Results}

A final sample of $n=4080$ adults aged $60+$ years included an oversample of older adults relative to the general population with a $69 \%$ of the population living in rural areas, 54\% women, and 52\% with primary or lower education and another $30 \%$ with monastic education (Table 1). $46 \%$ were not currently married. Noting the challenges with financing of health care in Myanmar, 65\% reported relying on their children or relatives for financial support.

Table 2 reports the level of social ties by health outcomes. The social ties score was not normally distributed, so differences in Table 2 are based on distributions of the score by the variable of interest. For each of the proxy health care indicators-the patterns generally showed higher level of social ties and better health and functioning, albeit the overall difference in means not statistically significant. For example, higher percentages of people with low social ties scores (scores of 1 or 2) reported fair/poor/very poor health with the overall social ties score higher in those reporting good health (3.29) compared to poor health (3.17)

From the logistic regression analyses, respondents who reported having a good memory had 1.2 times higher odds of high versus low social ties than respondents reporting poor memory (Table 3). Similar results were found for selfreported health. Those with walking difficulties had lower odds of having a high social ties score and may have contributed to limiting social contacts. People who receive regular assistance and those who provided care for others in their household had higher odds of having high social ties scores. Since almost all people limited in performing usual activities due to illnesses/injuries received assistance, they also had higher odds of high social ties scores. No difference was seen in the odds of high versus low social ties between those reporting bodily pain and those who did not.

\section{Discussion}

A range of health policy decisions and actions in Myanmar since 2015 have begun to make concrete impacts and progress in strengthening the NCD responses 
Table 1. 2012 Myanmar Aging Study respondent characteristics $(\mathrm{n}=4080)$.

\begin{tabular}{|c|c|c|}
\hline & \multicolumn{2}{|c|}{ Weighted } \\
\hline & $\mathbf{n}$ & $\%$ \\
\hline Total & 4080 & 100.0 \\
\hline \multicolumn{3}{|l|}{ Age years } \\
\hline $60-64$ & 1151 & 28.2 \\
\hline $65-69$ & 961 & 23.6 \\
\hline $70-74$ & 779 & 19.1 \\
\hline $75+$ & 1189 & 29.1 \\
\hline \multicolumn{3}{|l|}{ Residence } \\
\hline Urban & 1282 & 31.4 \\
\hline Rural & 2798 & 68.6 \\
\hline \multicolumn{3}{|l|}{ Sex } \\
\hline Men & 1875 & 46.0 \\
\hline Women & 2205 & 54.0 \\
\hline \multicolumn{3}{|l|}{ Education } \\
\hline No education & 898 & 22.0 \\
\hline Primary & 1219 & 29.9 \\
\hline Middle & 395 & 9.7 \\
\hline High school/vocational school/college & 344 & 8.4 \\
\hline Monastic/other & 1224 & 30.0 \\
\hline \multicolumn{3}{|l|}{ Marital status } \\
\hline Single (never married) & 185 & 4.5 \\
\hline Currently married & 2213 & 54.2 \\
\hline Separate/divorced/widowed & 1682 & 41.3 \\
\hline \multicolumn{3}{|l|}{ Important source of support } \\
\hline Work (own and/or spouse's) & 974 & 23.9 \\
\hline Savings (own and/or spouse's) & 349 & 8.6 \\
\hline Pension (own and/or spouse's) & 110 & 2.7 \\
\hline Children & 2400 & 58.8 \\
\hline Relatives/non-relatives & 247 & 6.0 \\
\hline
\end{tabular}

Table 2. Percentage distribution of the social ties score $(0=$ low; $4=$ high $)$, by the proxy health and functioning variables $(\mathrm{n}=4080), 2012$ Myanmar Aging Study.

\begin{tabular}{cccccccc}
\hline & \multicolumn{6}{c}{ Social ties score } \\
\cline { 2 - 8 } & $\mathbf{1}$ & $\mathbf{2}$ & $\mathbf{3}$ & $\mathbf{4}$ & Total & p-value \\
\hline Total & 2.52 & 16.57 & 38.61 & 42.30 & 100.0 & \\
\hline
\end{tabular}




\begin{tabular}{|c|c|c|c|c|c|c|c|}
\hline \multicolumn{8}{|l|}{ Continued } \\
\hline \multirow{2}{*}{$\begin{array}{l}\text { Self-reported } \\
\text { health }\end{array}$} & Very good/Good & 1.76 & 13.75 & 38.71 & 45.78 & 100.0 & 0.0001 \\
\hline & Fair/Poor/Very poor & 2.90 & 18.01 & 38.56 & 40.53 & 100.0 & \\
\hline \multirow{2}{*}{ Memory } & Very good/Good & 1.62 & 14.31 & 38.06 & 46.01 & 100.0 & $<0.0001$ \\
\hline & Fair/Poor/Very poor & 3.07 & 17.96 & 38.94 & 40.02 & 100.0 & \\
\hline $\begin{array}{l}\text { Take care } \\
\text { of other }\end{array}$ & Yes & 0.58 & 12.57 & 41.28 & 45.57 & 100.0 & $<0.0001$ \\
\hline $\begin{array}{l}\text { household } \\
\text { member }\end{array}$ & No & 3.14 & 17.86 & 37.75 & 41.25 & 100.0 & \\
\hline \multirow{2}{*}{$\begin{array}{l}\text { Walking } \\
\text { difficulties }\end{array}$} & A lot/Cannot do & 6.93 & 21.75 & 35.31 & 36.01 & 100.0 & $<0.0001$ \\
\hline & Some/None & 1.64 & 15.55 & 39.26 & 43.55 & 100.0 & \\
\hline \multirow{2}{*}{$\begin{array}{l}\text { Receive regular } \\
\text { assistance }\end{array}$} & Yes & 2.31 & 15.17 & 37.65 & 44.88 & 100.0 & $<0.0001$ \\
\hline & No & 2.89 & 19.12 & 40.35 & 37.64 & 100.0 & \\
\hline \multirow{2}{*}{$\begin{array}{c}\text { Illnesses/injuries } \\
\text { limited usual } \\
\text { activities }\end{array}$} & Yes & 2.39 & 16.47 & 36.66 & 44.49 & 100.0 & 0.2098 \\
\hline & No & 2.58 & 16.62 & 39.61 & 41.19 & 100.0 & \\
\hline \multirow{2}{*}{ Bodily pains } & Moderate/Severe & 2.16 & 18.19 & 39.10 & 40.55 & 100.0 & 0.3528 \\
\hline & None/Mild & 2.62 & 16.12 & 38.47 & 42.79 & 100.0 & \\
\hline
\end{tabular}

Table 3. Summary of logistic regression analysis (odds ratios and 95\% confidence intervals) for predictors of high versus low social ties for proxy health service indicators, controlling for age, sex and education.

\begin{tabular}{|c|c|c|c|c|}
\hline Effect & Response categories & OR & \multicolumn{2}{|c|}{ 95\% C.I. } \\
\hline Self reported health & $\begin{array}{l}\text { Very good/Good vs } \\
\text { Fair/Poor/Very poor }\end{array}$ & $1.151^{\star}$ & 1.002 & 1.323 \\
\hline Memory & $\begin{array}{l}\text { Very good/Good vs } \\
\text { Fair/Poor/Very poor }\end{array}$ & $1.199^{*}$ & 1.052 & 1.367 \\
\hline $\begin{array}{l}\text { Take care of other } \\
\text { household members }\end{array}$ & Yes vs No & $1.253^{*}$ & 1.091 & 1.440 \\
\hline Walking difficulties & A lot/Cannot do vs Some/None & $0.583^{\star}$ & 0.491 & 0.693 \\
\hline Receive regular assistance & Yes $v s$ No & $1.329^{*}$ & 1.174 & 1.504 \\
\hline $\begin{array}{l}\text { Illnesses/injuries limited } \\
\text { usual activities }\end{array}$ & Yes vs No & $1.191^{\star}$ & 1.047 & 1.355 \\
\hline Bodily pains & Moderate/Severe vs None/Mild & 1.006 & 0.868 & 1.166 \\
\hline
\end{tabular}

*Significant.

within the health system. Continued progress in health systems strengthening will be needed to respond to the growing adult population and the steady and continued rise in the burden of NCDs in the country [8]. Similar efforts would be required to improve the financial protection systems related to addressing health care expenses and might include innovative policy mechanisms around 
social networks [28].

The results presented here offer a national level perspective on how social networks contribute to healthier populations through a set of proxy indicators, like self-rated health and cognitive decline, known to be associated with many health outcomes (for example, pain, disability, illness and mortality) and to be predictors of health care utilization (self-care, informal caregiving, and receipt of formal health care services) [29] [30] [31] [32] [33]. While the impacts of social networks in this analysis are modest, they may be underestimated, and offer another potential avenue to contribute to the government's Universal Health Coverage goals and NCDs targets. Noting the rise in burden from NCDs and common risks, like hypertension, high body mass index and poverty, social networks may play an integral part of addressing NCDs within Myanmar's road to sustainable growth and poverty reduction [14 (pp. 18)] [34] [35] [36]. This also relates to the NHP Program Area \#3.6 (Life Cycle Approach-"Elderly" Health Care) where both medical and non-medical factors that support healthier populations and efficient use of health care are assessed to inform activities on the NHP action plan during the remaining year of the current NHP (2017-21). The proposed analyses were adjusted for sex, to address NHP Program Area \#8.12 (Addressing Determinants of Health; Gender and Women Health) and Program Area \#7.3 (Research on Non-Communicable Diseases).

Continuing to delay action on any of these risks will have considerable impact on health and social systems [37], and would hamper efforts to achieve UHC in the next decade. Yet Myanmar's policies are generating action, which in turn is being turned into evidence to inform the next planned policy cycle, such as the current National Health Plan (2017-2021) update for 2022 to 2026, and the same for the current NCD Strategic Action Plan (2017-2021) update. These have been active and impactful documents being translated into action plans and concrete improvements for NCDs and older adults. The recent attention to NCDs as a result of COVID could leverage now to help shift future approaches to addressing NCDs.

While positive gains have been made at the primary care level for preventive care, health care expenses from hospitalization continues to be a significant burden for many households in Myanmar [38]. Social relationships, both quantity and quality, are known to affect health outcomes and could be an important factor in improving access, mitigating costs and achieving policy goals in Myanmar [15] until more concrete progress is made on the financial protection elements related to universal health coverage [39].

Social networks are intertwined with the social determinants of health which we know are amenable to political interventions and are thereby dependent on political action [23] [40] [41]. In turn, the combination of political and economic factors influences what is included in policies related to NCDs [42] and universal health coverage [43].

While clinicians also need to address the social determinants of health when seeing patients, [44] most of the factors contributing to health fall outside the 
formal health system, like social networks. A consistent message of social justice and evidence-based policies can be used to engage government and others in action on social determinants of health [45]. Infectious disease pandemics, like the one we are currently experiencing with COVID-19, coupled with the endemicity of NCDs, exposed fundamental elements of society and highlighting that things can be done differently, and the important role of government in ensuring social and economic policies decrease health inequalities [46]. The findings from this study show small differences but consistent patterns in support of the positive role of social networks on factors that are known to influence health and health care utilization. Policy that support uptake of "best buys" to reduce NCD burden, and that nudge individuals and populations into better health choices and better self-management of their chronic conditions have the potential to make significant contributions to achieving UHC.

Where needed, social networks may also help nudge persons who need care, to access health care services. There is a need for health systems strengthening with a focus on establishing the essential building blocks for health systems, particularly at the primary healthcare level, where many older adults would be first accessing health care. This is where screening and application of "best buys" provide the biggest return on investment [47]. At the same time, social care systems need to be developed in parallel, and the two systems integrated. This integration has the potential to better address the care needs for older adult populations in Myanmar. For the health system, robust health workforce training, capacity building and community outreach, public health capacity and leadership at the national level, and improved health data monitoring and surveillance systems are needed. For the social system, the roll-out of a pension in Myanmar in 2017 was a first positive step. Strengthening social networks as well as social protection systems and labour laws that improve the economic status of populations have the potential to influence the burdens placed on the government from providing UHC making that endeavour more achievable.

\section{Limitations}

The results shown here are from cross-sectional data, so it could be that the direction of the relationships found here might be reversed. For example, persons with better cognition or physical functioning might be better able to maintain their social ties and obligations than persons who are beginning to experience decrements in cognitive or physical functioning. While this study provides much needed data on older adults, evidence is building to show that the onset of chronic disease is at earlier ages in lower income countries like Myanmar [48], so we may have missed an important age period (adults aged 40 - 59) that would be helpful in examining the fuller impact of social networks on health outcomes. The set of variables we used to define social ties or social networks were limited by what was available for secondary analyses, as opposed to prospectively identifying and using a robust measurement tool for data collection (see for example 
[49]). Given the social and economic changes in many parts of the country in recent years, accounting for these changes, noting the year of data collection, would be needed when interpreting results from this study.

\section{Conclusions}

Social networks may help maintain and accelerate the progress that has been made across Myanmar over the past five years in non-communicable disease prevention and management from training on the WHO Package of Essential NCDs (WHO PEN) provided at government facilities in all 330 townships across the country [50]. As much as government health spending has increased since 2012 to address the changing health needs of the Myanmar population, including more policy attention and budget directed to NCDs since 2015, the pace of increase may need to quicken further to meet targets in the current and future National Health Plan [14]. Similarly, established and innovative methods will be needed to strengthen its NCD response via the next National Strategic Plan for Prevention and Control of NCDs (2022-2026). However, we have seen that actions taken in primary care settings may contribute to significant increases in care at tertiary care facilities in Myanmar [11]. In turn, the subsequent health costs are largely borne by individuals and families as out-of-pocket costs. Without more robust financial risk pooling mechanisms, these out-of-pocket payments will also directly impact on the government's goal of achieving universal health coverage by the year 2030. Efforts to improve risk pooling systems may need to include approaches to strengthen social networks as one mechanism to address health and health care use, which in turn supports individuals to get the quality care they need that "does not result in financial hardship" ([14], p. 20).

Note: Post-01 Feb 2021, the health systems have been under considerable threat with significant implications for health care services for any health conditions.

\section{Acknowledgements}

We thank Dr Paul Ong for his contributions to the development of this manuscript and to the work that underpinned the content.

\section{Conflicts of Interest}

The authors declare no conflicts of interest regarding the publication of this paper.

\section{References}

[1] WHO (2019) Global Spending on Health: A World in Transition. World Health Organization, Geneva. https://apps.who.int/iris/bitstream/handle/10665/330357/WHO-HIS-HGF-HF-Wor kingPaper-19.4-eng.pdf?ua=1

[2] WHO. Global Health Expenditure Database. http://apps.who.int/nha/database/country profile/Index/en

[3] Van Rooijen, M., Myint, C.Y., Pavlova, M. and Groot, W. (2018) Health Insurance 
in Myanmar: The Views and Perception of Healthcare Consumers and Health System Informants on the Establishment of a Nationwide Health Insurance System. Risks, 6, Article No. 81. https://doi.org/10.3390/risks6030081

[4] Myint, C.Y., Pavlova, M. and Groot, W. (2019) Health Insurance in Myanmar: Knowledge, Perceptions, and Preferences of Social Security Scheme Members and General Adult Population. The International Journal of Health Planning and Management, 34, 346-369. https://doi.org/10.1002/hpm.2643

[5] Myint, C.Y., Pavlova, M. and Groot, W. (2019) Patterns of Health Care Use and Out-of-Pocket Payments among General Population and Social Security Beneficiaries in Myanmar. BMC Health Services Research, 19, Article No. 258.

https://doi.org/10.1186/s12913-019-4071-8

[6] Van Damme, W., Van Leemput, L., Por, I., Hardeman, W. and Meessen, B. (2004) Out-of-Pocket Health Expenditure and Debt in Poor Households: Evidence from Cambodia. Tropical Medicine \& International Health, 9, 273-280. https://doi.org/10.1046/j.1365-3156.2003.01194.x

[7] Joe, W. (2015) Distressed Financing of Household Out-of-Pocket Health Care Payments in India: Incidence and Correlates. Health Policy and Planning, 30, 728-741. https://doi.org/10.1093/heapol/czu050

[8] Institute for Health Metrics and Evaluation (2019) Global Burden of Disease Study 2019. University of Washington, Seattle. http://ghdx.healthdata.org/gbd-results-tool

[9] Krisha, A. (2019) Tackling Non-Communicable Diseases to Achieve Universal Health Coverage in Myanmar. HelpAge International Myanmar 2019.

http://themimu.info/sites/themimu.info/files/assessment file attachments/NCDs p olicy brief FINAL.pdf

[10] Maung, K.T., Kowal, P., Ng, N. and Krisha, A. (2019) The Road to Universal Health Coverage in Myanmar Runs through Non-Communicable Disease Risk Factors: Supporting Evidence from WHO in 2009 and 2014 and the Global Burden of Disease Study 2016. Health, 11, 1206-1223.

https://www.scirp.org/pdf/Health 2019092716142688.pdf https://doi.org/10.4236/health.2019.119094

[11] Swe, E.E., Htet, K.K.K., Thekkur, P., Aung, L.L., Aye, L.L. and Myint, T. (2020) Increasing Trends in Admissions Due to Non-Communicable Diseases over 2012 to 2017: Findings from Three Large Cities in Myanmar. Tropical Medicine and Health, 48, Article No. 24. https://doi.org/10.1186/s41182-020-00209-8

[12] Khaing, I.K., Malik, A., Oo, M. and Hamajima, N. (2015) Health Care Expenditure of Household in Magway, Myanmar. Nagoya Journal of Medical Science, 77, 203 212. https://www.ncbi.nlm.nih.gov/pmc/articles/PMC4361522/

[13] United Nations Population Division (2019) World Population Prospects: The 2019 Revision. UN, New York.

[14] MoHS (2017) Myanmar National Health Plan 2017-2021. Ministry of Health and Sports, Nay Pyi Taw.

http://mohs.gov.mm/Main/content/publication/national-health-plan-2017-2021-en g

[15] Umberson, D. and Karas Monte, J. (2010) Social Relationships and Health: A Flashpoint for Health Policy. Journal of Health and Social Behavior, 51, S54-S66. https://doi.org/10.1177/0022146510383501

[16] Schröders, J., Dewi, F.S.T., Nilsson, M. and Nichter, M. (2020) Effects of Social Network Diversity in the Disablement Process: A Comparison of Causal Inference Methods and an Outcome-Wide Approach to the Indonesian Family Life Surveys, 
2007-2015. International Journal for Equity in Health, 19, Article No. 128. https://doi.org/10.1186/s12939-020-01238-9

[17] Perkins, J.M., Subramanian, S.V. and Christakis, N.A. (2015) Social Networks and Health: A Systematic Review of Sociocentric Network Studies in Low- and MiddleIncome Countries. Social Science \& Medicine, 125, 60-78. https://doi.org/10.1016/j.socscimed.2014.08.019

[18] Stokes, J.E. (2020) Social Integration, Daily Discrimination, and Biological Markers of Health in Mid- and Later Life: Does Self-Esteem Play an Intermediary Role? Innovation in Aging, 4, igaa026. https://doi.org/10.1093/geroni/igaa026

[19] Wright, K. (2016) Social Networks, Interpersonal Social Support, and Health Outcomes: A Health Communication Perspective. Frontiers in Communication, 1, Article No. 10. https://doi.org/10.3389/fcomm.2016.00010

[20] World Economic Forum (WEF) (2017) Human-Centric Health: Behaviour Change and the Prevention of Non-Communicable Diseases. World Economic Forum, Geneva. http://www3.weforum.org/docs/IP/2016/HE/HCH Report2017.pdf

[21] Schwamm, L.H. (2018) The Communicable Nature of Non-Communicable Diseases. Lancet Neurol, 17, 665. https://doi.org/10.1016/S1474-4422(18)30216-3

[22] MoHS (2017) National Strategic Plan for Prevention and Control of NCDs (20172021). Ministry of Health and Sports, Nay Pyi Taw.

http://mohs.gov.mm/su/MyCBSF

[23] WHO (2013) Noncommunicable Diseases and Social Determinants of Health. World Health Organization, Geneva.

https://apps.who.int/iris/bitstream/handle/10665/126794/ncd.pdf?sequence=8\&isAll owed $=\mathrm{y}$

[24] WHO (2020) Global Action Plan for the Prevention and Control of Noncommunicable Diseases 2013-2020. World Health Organization, Geneva.

[25] Knodel, J. (2013) The Situation of Older Persons in Myanmar. Results from the 2012 Survey of Older Persons. HelpAge International Myanmar, Yangon.

https://deepblue.lib.umich.edu/bitstream/handle/2027.42/100343/Myanmar\%20rep ort.pdf? sequence $=1$ \&isAllowed $=\mathrm{y}$

[26] Kowal, P. and Ng, N. (2010) Social Networks, Health and Well-Being: Evidence from SAGE. WHO, Geneva.

https://www.researchgate.net/publication/274701434 Social networks health and well-being Evidence from SAGE

[27] Kowal, P. (2016) Social Networks and Health Care Utilization. In: He, W., Goodkind, D. and Kowal, P., Eds., An Aging World: 2015, International Population Reports, U.S. Government Publishing Office, Washington DC, 78.

[28] Falk, H., Skoog, I., Johansson, L., Guerchet, M., Mayston, R., Hörder, H., Prince, M. and Prina, A.M. (2017) Self-Rated Health and Its Association with Mortality in Older Adults in China, India and Latin America-A 10/66 Dementia Research Group Study. Age and Ageing, 46, 932-939. https://doi.org/10.1093/ageing/afx126

[29] Fernández-Olano, C., López-Torres Hidalgo, J.D., Cerdá-Díaz, R., Requena-Gallego, M., Sánchez-Castaño, M., Urbistondo-Cascales, L. and Otero-Puime, A. (2006) Factors Associated with Health Care Utilization by the Elderly in a Public Health Care System. Health Policy, 75, 131-139. https://doi.org/10.1016/j.healthpol.2005.02.005

[30] Fong, J.H. and Kok, Z.C. (2020) Does Subjective Health Matter? Predicting Overall and Specific ADL Disability Incidence. Archives of Gerontology and Geriatrics, 90, Article ID: 104169. https://doi.org/10.1016/j.archger.2020.104169 
[31] DeSalvo, K.B., Jones, T.M., Peabody, J., et al. (2009) Health Care Expenditure Prediction with a Single Item, Self-Rated Health Measure. Medical Care, 47, 440-447. https://doi.org/10.1097/MLR.0b013e318190b716

[32] Halford, C., Wallman, T., Welin, L., et al. (2012) Effects of Self-Rated Health on Sick Leave, Disability Pension, Hospital Admissions and Mortality. A PopulationBased Longitudinal Study of Nearly 15,000 Observations among Swedish Women and Men. BMC Public Health, 12, Article No. 1103. https://doi.org/10.1186/1471-2458-12-1103

[33] Schnittker, J., and Bacak, V. (2014) The Increasing Predictive Validity of Self-Rated Health. PLoS ONE, 9, e84933. https://doi.org/10.1371/journal.pone.0084933

[34] Christakis, N.A. and Fowler, J.H. (2007) The Spread of Obesity in a Large Social Network over 32 Years. The New England Journal of Medicine, 357, 370-379. https://doi.org/10.1056/NEJMsa066082

[35] Shaya, F.T., Chirikov, V.V., Mullins, C.D., et al. (2013) Social Networks Help Control Hypertension. The Journal of Clinical Hypertension, 15, 34-40. https://doi.org/10.1111/jch.12036

[36] Reeves, D., Blickem, C., Vassilev, I., Brooks, H., Kennedy, A., Richardson, G., et al. (2014) The Contribution of Social Networks to the Health and Self-Management of Patients with Long-Term Conditions: A Longitudinal Study. PLoS ONE, 9, e98340. https://doi.org/10.1371/journal.pone.0098340

[37] Bloom, D.E., Chatterji, S., Kowal, P., et al. (2015) Macroeconomic Implications of Population Ageing and Selected Policy Responses. The Lancet, 385, 649-657. https://doi.org/10.1016/S0140-6736(14)61464-1

[38] Myint, C., Pavlova, M. and Groot, W. (2019) Catastrophic Health Care Expenditure in Myanmar: Policy Implications in Leading Progress towards Universal Health Coverage. International Journal for Equity in Health, 18, Article No. 118. https://doi.org/10.1186/s12939-019-1018-y

[39] Wagstaff, A. and Neelsen, S. (2020) A Comprehensive Assessment of Universal Health Coverage in 111 Countries: A Retrospective Observational Study. The Lancet Global Health, 8, E39-E49. https://doi.org/10.1016/S2214-109X(19)30463-2

[40] Bambra, C., Fox, D. and Scott-Samuel, A. (2005) Towards a Politics of Health. Health Promotion International, 20, 187-193. https://doi.org/10.1093/heapro/dah608

[41] Gilson, L., Orgill, M. and Shroff, Z.C. (2018) A Health Policy Analysis Reader: The Politics of Policy Change in Low- and Middle-Income Countries. World Health Organization, Geneva. https://www.who.int/alliance-hpsr/resources/publications/Alliance-HPA-Reader-w eb.pdf

[42] Buse, K., Tanaka, S. and Hawkes, S. (2017) Healthy People and Healthy Profits? Elaborating a Conceptual Framework for Governing the Commercial Determinants of Non-Communicable Diseases and Identifying Options for Reducing Risk Exposure. Globalization and Health, 13, Article No. 34. https://doi.org/10.1186/s12992-017-0255-3

[43] Savedoff, W.D., de Ferranti, D., Smith, A.L. and Fan, V. (2012) Political and Economic Aspects of the Transition to Universal Health Coverage. The Lancet, 380, 924932. https://doi.org/10.1016/S0140-6736(12)61083-6

[44] Andermann, A. (2016) Taking Action on the Social Determinants of Health in Clinical Practice: A Framework for Health Professionals. Canadian Medical Association Journal, 188, E474-E483. https://doi.org/10.1503/cmaj.160177

[45] Marmot, M. (2017) Commentary: Social Determinants and the Health Gap: Creat- 
ing a Social Movement. International Journal of Epidemiology, 46, 1335-1339. https://doi.org/10.1093/ije/dyx182

[46] Marmot, M. (2020) Society and the Slow Burn of Inequality. The Lancet, 395, 1413 1414. https://doi.org/10.1016/S0140-6736(20)30940-5

[47] Isaranuwatchai, W., Teerawattananon, Y., Archer, R.A., et al. (2020) Prevention of non-Communicable Disease: Best Buys, Wasted Buys, and Contestable Buys. British Medical Journal, 368, m141.

[48] Nugent, R., Bertram, M.Y., Jan, S., et al. (2018) Investing in Non-Communicable Disease Prevention and Management to Advance the Sustainable Development Goals. The Lancet, 391, 2029-2035. https://doi.org/10.1016/S0140-6736(18)30667-6

[49] Dhand, A., White, C.C., Johnson, C., Xia, Z. and De Jager, P.L. (2018) A Scalable Online Tool For Quantitative Social Network Assessment Reveals Potentially Modifiable Social Environmental Risks. Nature Communications, 9, Article No. 3930. https://doi.org/10.1038/s41467-018-06408-6

[50] HelpAge International Myanmar (2020) https://europa.eu/capacity4dev/capacity-building-in-public-health-for-development /documents/sphc-myanmar-preparedness-and-responsiveness-ncd-service-delivery -pen-clinics 


\section{Supplemental}

Table S1. Burden of disease profile (deaths, YLD and DALYs) by broad disease groupings, for 1990 and 2019.

\begin{tabular}{ccccccc}
\hline & Deaths & \multicolumn{2}{c}{$\begin{array}{c}\text { Years lived with } \\
\text { disability }\end{array}$} & DALYs \\
\hline $\begin{array}{c}\text { Broad disease groupings } \\
\text { Communicable, }\end{array}$ & 1990 & 2019 & 1990 & 2019 & 1990 & 2019 \\
$\begin{array}{c}\text { maternal, neonatal, and } \\
\text { nutritional diseases }\end{array}$ & $43.1 \%$ & $18.6 \%$ & $26.0 \%$ & $13.9 \%$ & $53.6 \%$ & $25.7 \%$ \\
$\begin{array}{c}\text { Non-communicable diseases } \\
\text { Injuries }\end{array}$ & $48.5 \%$ & $75.3 \%$ & $70.5 \%$ & $79.0 \%$ & $37.6 \%$ & $65.4 \%$ \\
& $8.3 \%$ & $6.1 \%$ & $3.5 \%$ & $7.1 \%$ & $8.7 \%$ & $8.9 \%$ \\
\hline
\end{tabular}

${ }^{\star}$ YLD = Years lived with Disability; DALY = Disability-Adjusted Life Year.

Table S2. NCD targets in the Myanmar NCD national strategic plan.

\begin{tabular}{|c|c|c|c|}
\hline \multirow{2}{*}{ Indicators with targets } & \multirow{2}{*}{$\begin{array}{l}\text { Baseline levels } \\
\text { (2010 WHO } \\
\text { estimates) }\end{array}$} & \multicolumn{2}{|c|}{ Targets } \\
\hline & & 2021 & 2025 \\
\hline $\begin{array}{l}\text { 1) Relative reduction in the unconditional } \\
\text { probability of dying between } 30 \text { and } 70 \text { years from } \\
\text { cardiovascular disease, cancer, diabetes or chronic } \\
\text { respiratory disease }\end{array}$ & 0.24 & $15 \%$ & $20 \%$ \\
\hline $\begin{array}{l}\text { 2) Relative reduction in the age standardized } \\
\text { prevalence of heavy episodic alcohol drinking } \\
\text { among adults (\%) }\end{array}$ & 10.3 & $5 \%$ & $10 \%$ \\
\hline $\begin{array}{l}\text { 3) Relative reduction in the prevalence of current } \\
\text { tobacco use in persons aged over } 15 \text { years (\%) }\end{array}$ & $\begin{array}{c}\text { Smoked-22 } \\
\text { Smokeless-29.7 }\end{array}$ & $5 \%$ & $10 \%$ \\
\hline $\begin{array}{l}\text { 4) Relative reduction in the prevalence of } \\
\text { insufficient physical activity among adults (\%) }\end{array}$ & 12.7 & $5 \%$ & $10 \%$ \\
\hline $\begin{array}{l}\text { 5) Relative reduction in the mean population } \\
\text { intake of salt/sodium (mgs/day) }\end{array}$ & Not available & $10 \%$ & $20 \%$ \\
\hline $\begin{array}{l}\text { 6) Relative reduction in the prevalence of raised } \\
\text { blood pressure (\%) }\end{array}$ & 28.9 & $10 \%$ & $20 \%$ \\
\hline $\begin{array}{l}\text { 7) Relative reduction in the prevalence of } \\
\text { overweight and obesity (\%) }\end{array}$ & $\begin{array}{l}\text { Overweight-25.4 } \\
\text { Diabetes-10.5 }\end{array}$ & Halt th & he rise \\
\hline $\begin{array}{l}\text { 8) Increase in the proportion of eligible people } \\
\text { receiving drug therapy and counselling } \\
\text { (including glycemic control) to prevent heart } \\
\text { attacks and strokes (\%) }\end{array}$ & $32(2014)$ & $25 \%$ & $50 \%$ \\
\hline $\begin{array}{l}\text { 9) Increase in the availability of affordable basic } \\
\text { technologies and essential medicines, including } \\
\text { generics, required to treat major NCDs in public } \\
\text { facilities (\%) }\end{array}$ & Not available & $50 \%$ & $80 \%$ \\
\hline
\end{tabular}




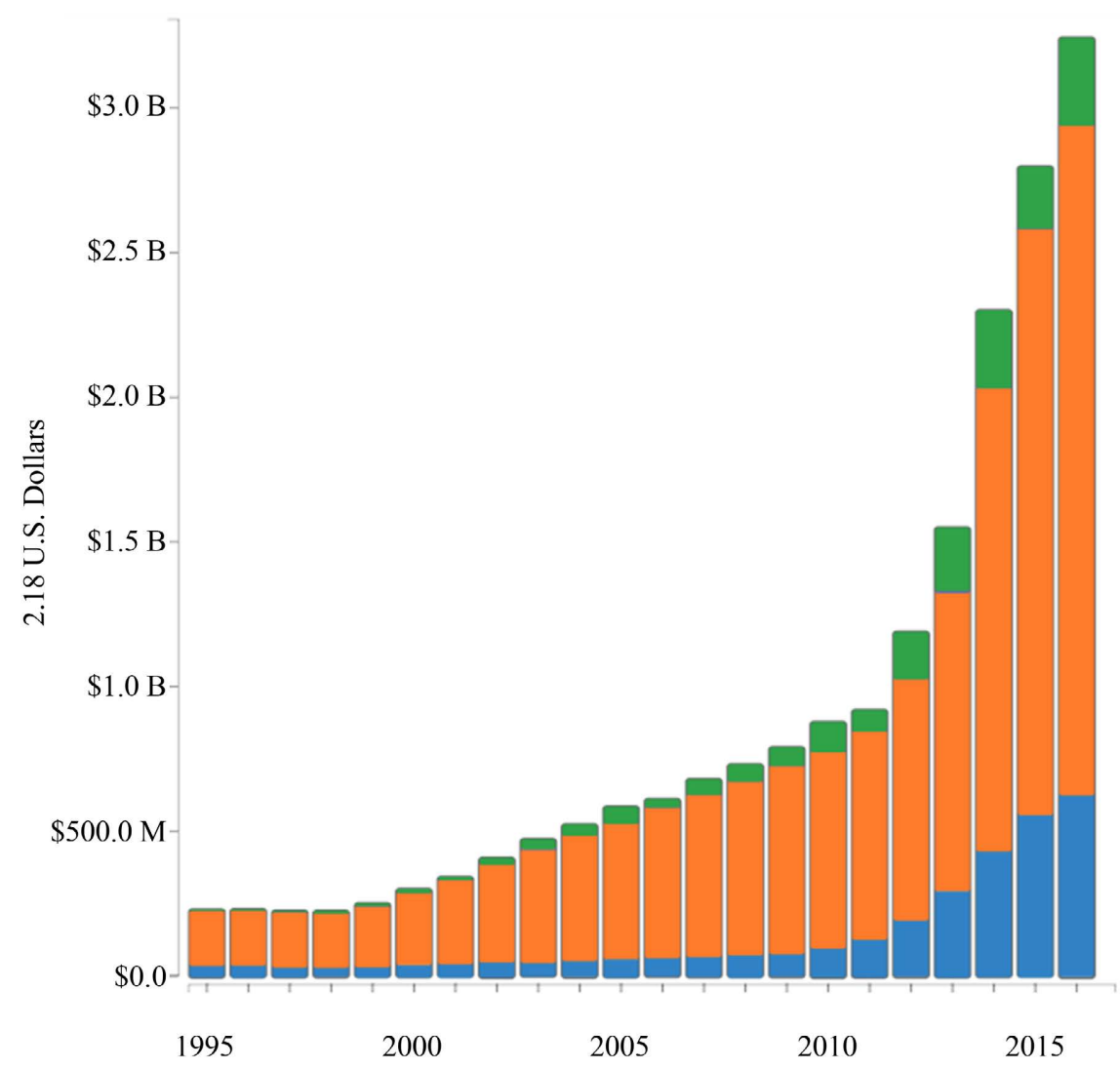

Figure S1. Health systems financing in Myanmar, 1995-2016 (Source: IHME 2017).

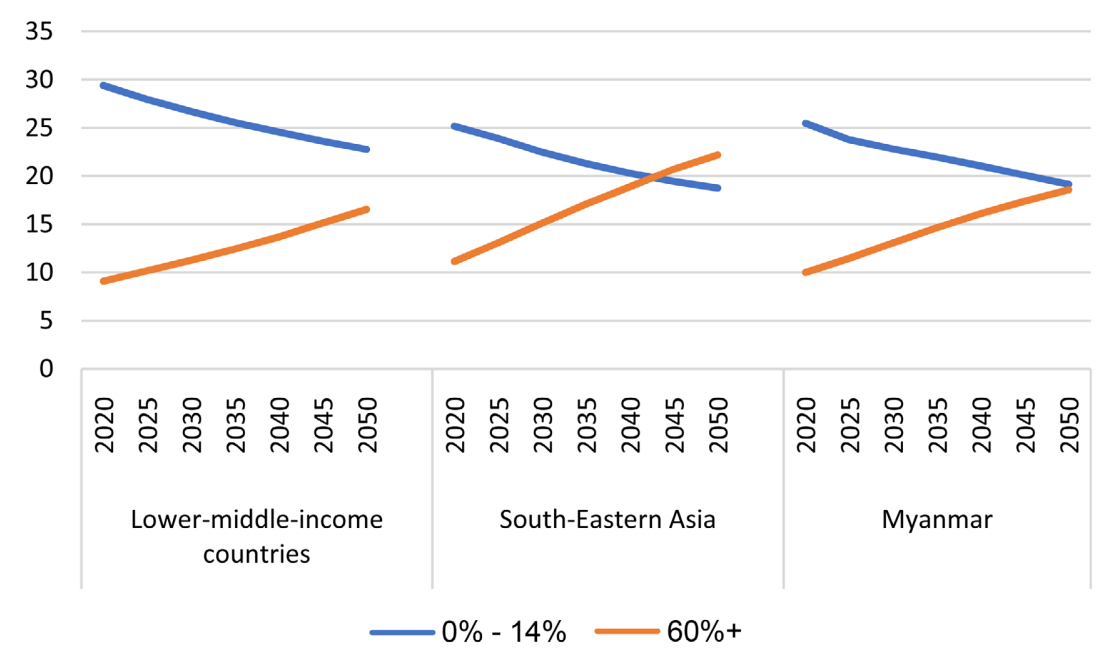

Figure S2. Percent of the population aged 0 - 14 and 60+ between 2020 and 2050, for lower-middle income countries, South-Eastern Asia and Myanmar. (Source: UN Population Division 2019). 